\title{
Overcoming the Adoption Barrier to Electric Flight
}

\author{
Nicholas K. Borer ${ }^{1}$, Craig L. Nickol' ${ }^{2}$, Frank P. Jones ${ }^{3}$, Richard J. Yasky ${ }^{4}$, Kurt Woodham ${ }^{5}$, Jared S. Fell ${ }^{6}$, Brandon \\ L. Litherland ${ }^{7}$ \\ NASA Langley Research Center, Hampton, Virginia 23681 \\ Patricia L. Loyselle ${ }^{8}$, Andrew J. Provenza ${ }^{9}$, Lee W. Kohlman ${ }^{10}$ \\ NASA Glenn Research Center, Cleveland, Ohio, 44135 \\ Aamod G. Samuel ${ }^{11}$ \\ NASA Armstrong Flight Research Center, Edwards, California 93523
}

\begin{abstract}
Electrically-powered aircraft can enable dramatic increases in efficiency and reliability, reduced emissions, and reduced noise as compared to today's combustion-powered aircraft. This paper describes a novel flight demonstration concept that will enable the benefits of electric propulsion, while keeping the extraordinary convenience and utility of common fuels available at today's airports. A critical gap in airborne electric propulsion research is addressed by accommodating adoption at the integrated aircraft-airport systems level, using a confluence of innovative but proven concepts and technologies in power generation and electricity storage that need to reside only on the airframe. Technical discriminators of this demonstrator concept include (1) a novel, high-efficiency power system that utilizes advanced solid oxide fuel cells originally developed for ultra-long-endurance aircraft, coupled with (2) a high-efficiency, high-power electric propulsion system selected from mature products to reduce technical risk, assembled into (3) a modern, high-performance demonstration platform to provide useful and compelling data, both for the targeted early adopters and the eventual commercial market.
\end{abstract}

$\begin{array}{llll}\text { COTS } & \text { Commercial, Off-The-Shelf } & \text { SOFC } & \text { Solid Oxide Fuel Cell } \\ \text { ICE } & \text { Internal Combustion Engine } & \text { STC } & \text { Supplemental Type Certificate } \\ \text { PEMFC } & \text { Proton Exchange Membrane Fuel Cell } & & \end{array}$

\section{Introduction}

The use of electric motors for aircraft propulsion is a topic of increasing interest in the aviation community, largely due to the significant increase in efficiency of these motors vs. traditional internal combustion engines (ICEs). For light aircraft, these motors are more compact, lighter, quieter, and far more reliable than the reciprocating combustion engines that are currently used for primary propulsion [1]. For larger aircraft, the relatively scale-invariant nature of efficiency vs. power level (and engine size) tends to enable more distributed propulsion

\footnotetext{
${ }^{1}$ Aerospace Engineer, Aeronautics Systems Analysis Branch, 1 N. Dryden St. MS 442, AIAA Senior Member.

2 <title>, Aeronautics Systems Analysis Branch, 1 N. Dryden St. MS 442, <AIAA member status>.

$3<$ title>, <branch>, <street address \& mail stop>, <AIAA member status>.

4 <title $>$, <branch $>$, <street address \& mail stop $>$, <AIAA member status $>$.

5 <title>, <branch >, <street address \& mail stop >, <AIAA member status $>$.

6 <title>, <branch>, <street address \& mail stop>, <AIAA member status $>$.

$7<$ title $>,\langle$ branch $>$, <street address \& mail stop $>,<$ AIAA member status $>$.

$8<$ title $>,\langle$ branch $>$, <street address \& mail stop $\rangle,<$ AIAA member status $>$.

${ }^{9}\langle$ title $\rangle,\langle$ branch $\rangle$, <street address \& mail stop $\rangle$, <AIAA member status $>$.

$10<$ title $>$, <branch >, <street address \& mail stop >, <AIAA member status $>$.

$11<$ title $>$, <branch>, <street address \& mail stop >, <AIAA member status $>$. 
architectures than seen with typical thermodynamic cycles used for propulsion [2, 3]. Distributed electric propulsion architectures can yield a net benefit in total efficiency due to synergistic airframe-propulsive coupling [4].

Ongoing electric aircraft development, research, and eventual production projects are focusing on the lowpower, low-range, limited utility platforms dedicated to the flight training market, as seen in the Airbus E-Fan [5] and the Pipistrel Alpha Electro [6]. These are seen as stepping-stone platforms by their parent companies for entrance into larger, more powerful aircraft. Other research projects, such as NASA's SCEPTOR program [7], are investigating integrated airframe-propulsion technologies (in this case, distributed electric propulsion) as a way to further increase the cruise efficiency available to electric aircraft, enabling higher speeds and longer ranges.

\section{A. Barriers to Adoption of Electric Aircraft}

Limits of the component technologies needed for electric aircraft are often cited as a reason that electric propulsion will remain a niche market for some time to come [8]. While there are certainly improvements needed within the electric aircraft system, the adoption of electric aircraft needs to consider not just the aircraft-specific components, but the environment and infrastructure in which the aircraft must operate. For this paper, the authors consider three major barriers that constrain the application of electric propulsion to aircraft, both within and external to the individual aircraft: 1) specific energy of onboard energy storage, 2) refueling and support infrastructure, and 3) certification.

\section{Specific Energy of Onboard Energy Storage}

The first major barrier, and the one that is most often cited, is the specific energy of the onboard energy storage system. Today's civil aircraft almost exclusively use refined petroleum products for onboard energy storage. The most common fuel for light aircraft reciprocating engines is a high-octane leaded aviation fuel [9] (i.e. 100 octane "low lead," or 100LL) that is related to high-octane automotive pump gasoline found at most filling stations (albeit with tetraethyl lead added to maintain compatibility with older, higher-power engines). Aircraft powered by gas turbine engines (and some compression-ignition reciprocating engine-powered aircraft) use "jet fuel" [10] (i.e. Jet A or Jet A-1) that is much like kerosene or diesel fuel. The specific energy of 100LL and Jet A is approximately $43.5 \mathrm{MJ} / \mathrm{kg}$ and $43 \mathrm{MJ} / \mathrm{kg}$, respectively.

Batteries are the predominant form of electricity storage for electrically-powered aircraft and other vehicles. Given that electric motors are often rated in Watts, the energy of batteries is typically quoted in terms of Watt-hours. Advanced battery formulations such as lithium-polymer yield hobby applications that approach $200 \mathrm{~W}-\mathrm{hrs} / \mathrm{kg}$ [11]. Current in-production vehicles, such as Tesla's Roadster [12] and Pipistrel's Taurus Electro motorglider [13], yield pack-level specific energy values of 132 and $113 \mathrm{~W}-\mathrm{hrs} / \mathrm{kg}$, respectively. Hence, the amount of energy per unit mass in a modern high-energy battery is about 60-100 times less than the equivalent mass in aviation fuels (by comparison, the specific energy values of 100LL and Jet A are approximately 12,000 W-hrs $/ \mathrm{kg}$ ). While significant research and development is being poured into higher-energy batteries, the low specific energy associated with batteries requires a very steep improvement to reach parity with the energy content of modern fuels on a mass basis.

Using mass of fuel vs. battery systems is not necessarily a fair comparison, however. From a pessimistic perspective, batteries are typically not fully discharged; this reduces the number of charge cycles they can experience or otherwise reduces their specific energy capacity. An $80 \%$ depth of discharge is a commonly used number to ensure sufficient charge/discharge cycles over the lifetime of the battery. In addition, fuel-burning aircraft that fly long distances benefit from the reduction in weight as fuel is depleted, as they need to produce less lift and therefore less induced drag for a given flight condition. Batteries are more or less constant-weight devices (with some exceptions, such as lithium-air batteries). However, from an optimistic perspective, the batteries are used to power electric motors that can be three times (or more) efficient than gasoline-powered engines, so only one-third of the total onboard energy is needed (neglecting mass effects) for the same range. Finally, many aircraft do not fly missions that require the use of all of the onboard fuel - commercial short-haul commuters and many light personal aircraft fly for only an hour or less to complete their missions, though they may have a fuel capacity for many hours of flight [14]. Hence, the 60-100 times deficit that batteries have in energy per unit mass may well only be a deficit of 10-20 times or less, depending on the mission. Other system-level benefits, such as reduced cooling mass, or the benefits associated with distributed electric propulsion, can further reduce the impact of this deficit. Still, it remains a daunting challenge, and one in which most current electric vehicle efforts are placing their focus (either through design of higher-energy batteries or focus on configurations/missions that use less energy).

\section{Refueling and Support Infrastructure}

There are nearly 20,000 public and private airports in the United States, with over 5,000 designated for public use. Of these, more than 3,000 are within the National Plan of Integrated Airport Systems (NPIAS, Figure 1) [15]. 
This airport system was largely subsidized by the rapid expansion of airfields during World War II. The Federal Aviation Administration (FAA) continues to subsidize NPIAS-listed airports through its trust fund (which includes revenue from fuel and passenger ticket taxes) and the Federal General Fund. These investments represent an opportunity for aircraft users, as they ensure proximity to local airports in any part of the United States. Conversely, they are also a barrier to the introduction of new technologies with infrastructure requirements that are incompatible with the current airport system, particularly any that require fuels that cannot be stored or dispensed in a manner consistent with today's liquid hydrocarbon paradigm. Given the remoteness and relatively sparse use of some of these airports, the business case of investing in electrical charging stations, pressurized and/or cryogenic storage tanks, battery "hot-swap" storage, or other alternative refueling/recharging concepts may be a daunting challenge for the municipalities and small businesses that provide traditional fuel services at many of these airports. Yet, without this investment, widespread adoption of electric aircraft that require specialized facilities may be stymied.

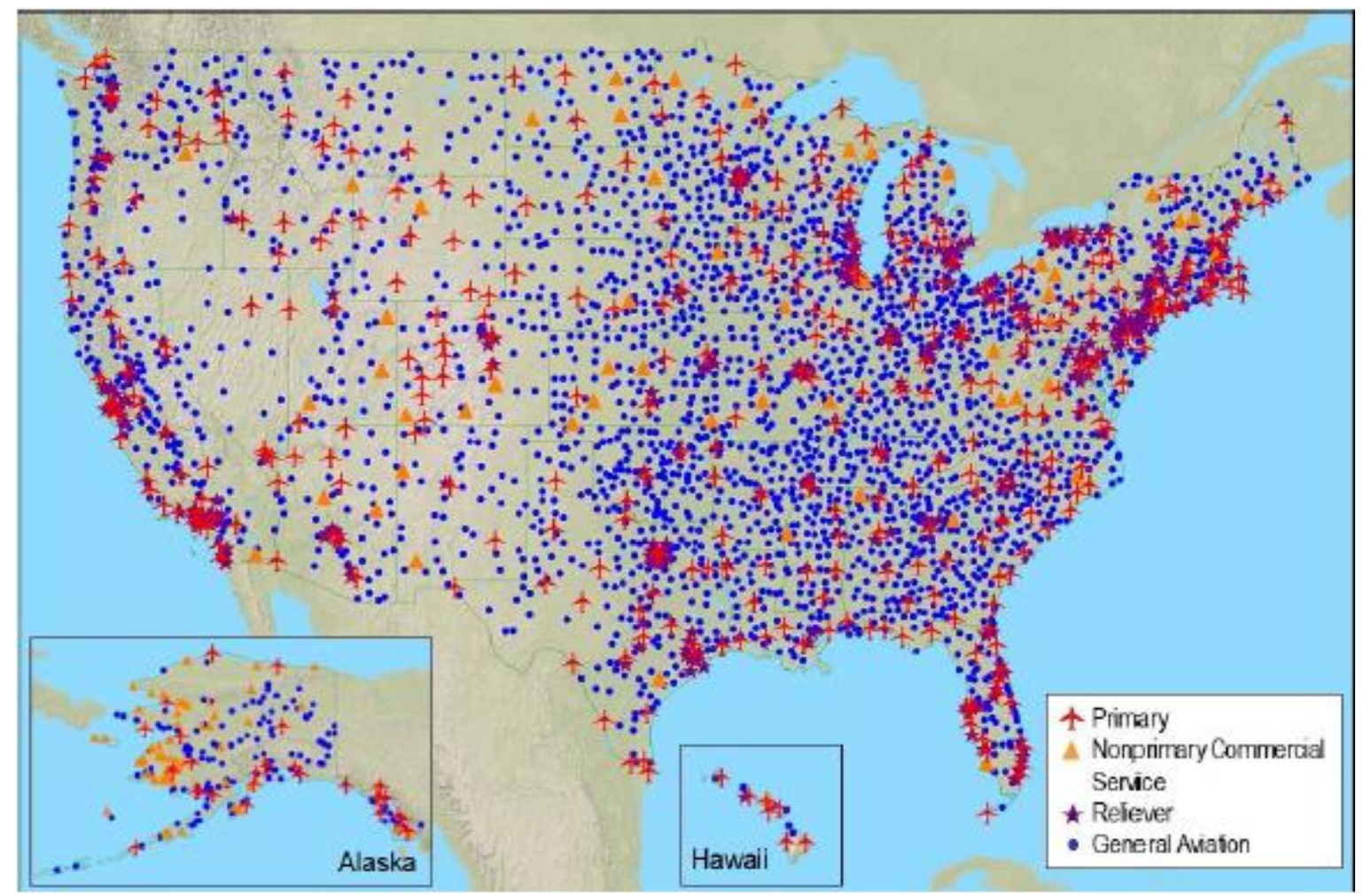

Figure 1: The National Plan of Integrated Airport Systems consisted of 3,380 airports in 2010 [15].

\section{Certification}

Commercial aviation, particularly in the United States, is considered one of the safest modes of transportation [16]. Operators and aircraft alike are subject to rigorous, mature certification standards that are the result of decades of experience. To maintain this exceptionally high level of safety, all but the smallest passenger-carrying aircraft must show that they are susceptible to less than one catastrophic failure per billion flight hours [17, 18]. Electric motors have a fairly long heritage, and there are few inherent safety or reliability issues. However, the energy storage and power distribution systems, and associated impact their potential failure modes may have on the aircraft, will need careful consideration. Demonstration of the high safety assurance levels required for certification will be costly and time-consuming. Furthermore, there is currently no basis in the United States for certification of aircraft that use electric power for primary propulsion. The FAA has indicated that it will enable certification of electricallypropelled aircraft in the future, likely through the use of consensus standards such as those being developed by ASTM International Committee F39 on Aircraft Systems [19]. However, these standards, and their incorporation into civil aviation rulemaking authorities (such as the FAA), are still in development. Until such standards and rules mature, there will be uncertainty associated with the performance, design, and safety requirements associated with aircraft that utilize electric propulsion. 


\section{B. Enabling the Transition to Electric}

Developing an aircraft that uses electric propulsion is, by itself, a technical challenge. It requires the successful integration of technologies that can safely yield appropriate performance at an acceptable cost. Yet, technical success may not be enough to enable current users to switch to electric propulsion, particularly if doing so causes other burdens. Performance alone will not guarantee success in the broader aviation market.

Current developers and manufacturers of electrically-propelled aircraft, such as Pipistrel, have targeted the overseas glider market, and more recently, the flight training market (as evidenced by the Pipistrel Alpha Electro and Airbus E-Fan). European manufacturers, in particular, have focused on these recreational flight markets, largely because of high aviation fuel prices (compared to the United States). These platforms have limited speed and utility, largely due to constraints on the weight and cost of the energy storage system (batteries), which do not scale favorably with the power requirements of larger, faster aircraft. Furthermore, training platforms can operate out of dedicated facilities (airports), circumventing the infrastructure barrier - they simply do not have the range or endurance to fly elsewhere. Companies such as Airbus and Pipistrel have goals to introduce larger, faster, longerrange aircraft as energy storage technology develops, but intend to use the training market as the first stepping stone. This is an appropriate, albeit lengthy, route towards larger adoption of electric aircraft.

At the opposite end of the spectrum, NASA has looked to the development of component technologies and conceptual design of large (hundreds of passengers) hybrid-electric aircraft [20]. These concepts use turboelectric generators for electrical power, and, depending on the particular technology target, may use either cryogenic or traditional liquid hydrocarbon fuels. The use of conventional fuels ensures compatibility with existing infrastructure, and generating electrical power from Brayton cycle gas turbines for use in high-efficiency electric motors improves the overall efficiency of the concept. Such concept studies are often meant to drive component technology development, such as NASA's recent solicitation for a megawatt-class non-cryogenic electric motor [21].

A promising approach for faster adoption of electrically-propelled aircraft is to consider something between the size of flight trainers and large transports, perhaps biased initially towards the light aircraft market. For success in this market, the vehicles will need to cruise at higher speeds, at longer ranges, and with larger payloads than required for flight training. Targeting light aviation as an "early adopter" market makes sense from a certification perspective. In the United States, light aircraft under 6,000 pounds need to demonstrate less than one catastrophic failure per million flight hours [17], which is 1,000 times less stringent than the requirement for larger commercial aircraft. Experience gained from the light aircraft market can provide data for future certification of larger commercial aircraft. This has occurred in the past for different technologies, ranging from GPS, flat-panel displays, and most recently, the use of consumer-grade tablet computers as electronic flight bags.

\section{Electric Power from Fuel}

The use of an infrastructure-friendly fuel, as opposed to a battery or gaseous/cryogenic source, ensures that the electric product will "drop in" to the existing infrastructure with little or no change in utility. At the power levels required for light aircraft $(<1 \mathrm{MW})$, turboelectric generators are less efficient and potentially costly from both an acquisition and operational standpoint. Instead, a promising energy storage mechanism for electric aircraft is the fuel cell. Fuel cells convert energy from a chemical fuel into electricity by combining the hydrogen in the fuel with oxygen, and produce water as a byproduct. If the fuel source is other than pure hydrogen, the fuel must be "reformed" by stripping the hydrogen from the fuel, which leads to additional byproducts in the exhaust. With ongoing development, fuel cells have promise to replace ICEs as they offer potential for higher efficiencies and lower emissions.

There are several different types of fuel cells, with the principal discriminator being the type of electrolyte. The selection of the electrolyte also determines whether hydrogen or oxygen ions will transport across the electrolyte. The typical fuel cells of interest in aerospace applications are Proton Exchange Membrane Fuel Cell (PEMFC) and Solid Oxide Fuel Cell (SOFC), as they tend to have higher efficiency and lower mass than others. PEMFCs operate at lower temperatures $\left(<100^{\circ} \mathrm{C}\right)$ than SOFCs $\left(600-800^{\circ} \mathrm{C}\right)$, enabling a faster start. Unfortunately, PEMFCs are best suited for operating on pure hydrogen, which can be an issue when the hydrogen source is a reformed hydrocarbon fuel. In this case, other products of the reformation process (especially sulfur and carbon monoxide) can "poison" the PEMFC. Hence, the SOFC is the preferred aerospace fuel cell when hydrocarbon fuels are used [22].

Overall, the use of a SOFC-enabled electric propulsion architecture has the most promise to enable transition to electric propulsion. The SOFC can reform traditional fuels into electricity at high efficiency, thus adding no infrastructure cost or utility penalty - the aircraft can use the exact same airports and fuel depots as before. The high efficiency of the SOFC vs. the ICE results in less fuel usage (and therefore lower operating costs), and is directly correlated with lower carbon emissions. In addition, the reduction in temperature of the SOFC reformer vs. ICE combustion leads to elimination of nitrogen oxides from the exhaust. Finally, a fuel cell architecture that uses 
infrastructure-friendly fuels enables hybrid power generation approach for larger aircraft that still may use combustion for primary propulsion, but instead generate electricity for onboard system use at a greatly increased efficiency over power extraction from the propulsion cycle.

\section{Objectives}

This paper documents the approach to select a concept for a low-cost, high-impact hybrid SOFC-electric demonstration aircraft to be flight-tested in future development efforts. The ultimate goal is to demonstrate a 50\% reduction in fuel cost for an appropriate light aircraft cruise profile (payload, range, speed, and altitude). This demonstrator will gather design and operational data (which will be made available to industry and regulators) to provide a path towards further development and certification.

\section{Technical Approach}

To develop an infrastructure-friendly electric propulsion demonstrator, the authors conducted an extensive exploration of viable demonstration aircraft candidates, along with the conceptual design and description of the systems necessary for successful demonstration. This was accomplished via a multidisciplinary, risk-driven approach to exploration and design.

\section{A. Demonstrator Decision Criteria}

The choice of demonstration aircraft is a critical part of identifying the requirements and constraints for the design of the SOFC-enabled electric propulsion architecture, as well as the overall demonstrator test program and risk matrix. In an effort to keep the demonstration system cost down, the team considered modifications to existing aircraft, rather than purpose-building a SOFC-electric aircraft from scratch. This approach also provides the demonstration program with a definitive performance and operations cost baseline for comparison. In selecting a demonstrator baseline, the team considered the following criteria:

- Airframe acquisition and NASA processing - This refers to the cost, schedule impact, and uncertainty associated with acquiring the baseline (unmodified) test aircraft, bringing it up to NASA airworthiness standards, and making the appropriate modifications.

- Propulsion (motor, propeller, and accessories) - This refers to the cost, schedule impact, and uncertainty associated with the acquisition, testing, and integration of the electric powertrain, including (if necessary) selecting an appropriate alternate propeller. The propeller is an important consideration, as many aircraft use engine oil as the working fluid for hydraulically-actuated constant-speed propellers, and an electric motor replacement would need an alternate means to control propeller RPM or blade pitch, if the baseline aircraft was so equipped.

- Power system (SOFC and balance of plant) - This refers to the cost, schedule impact, and uncertainty associated with the design, fabrication, testing, and integration of the hybrid SOFC-electric power system, including all support components (battery, plumbing, electrical lines, protection circuits, packaging and insulation, etc.).

- Number of US vs. foreign manufacturers for demonstrator and components - Given that the team will be proposing a flight demonstrator program to NASA, it is important to show that U.S. tax dollars are largely going to domestic institutions. Additionally, working with domestic companies can be preferable should any International Traffic in Arms Regulations (ITAR) or Export Administration Regulations (EAR) technology issues arise during the program.

- Mass and volume margin with new motor and power system - This refers to the excess mass and volume available in the aircraft as compared to the expected mass and volume of the power and propulsion system. More margin enables greater design flexibility, or use of cheaper components that may not be optimized for the application.

- Aircraft range at maximum gross weight - Given that the total empty weight of the aircraft will likely grow with these modifications, there will likely be less mass available for fuel. However, the increased efficiency of the power system will require less fuel for a given range.

- Cruise speed - Though speed is not a primary factor, potential retrofit concepts are more attractive if they enable users to get to their destinations at faster speeds. Hence, faster aircraft were considered more favorable, in addition to the other decision criteria.

- Safety of flight impact - This refers to potential hazards introduced to the aircraft and crew associated with integration and flight of the new power and propulsion architecture. Some demonstrator and 
integration choices (single vs. multi-engine, equipment required in crew compartment aft of crew, etc.) may adversely affect safety of flight.

- Public perception ("wow" factor) - A driving assumption to this research is to demonstrate performance and utility that will be appealing to early adopters. Concepts that score higher here are allencompassing, full flight demonstrators with compelling performance, particularly associated with the initial target market.

\section{B. Power System Development}

The power system is the key technology component of this demonstration. It must enable high efficiency from traditional infrastructure-friendly hydrocarbon fuels to meet the program goals. The Boeing Co., a partner to this demonstrator investigation, has been developing a regenerative SOFC-enabled flight-weight power system under the DARPA Vulture program that is lighter and more efficient than current fuel cell technology. It is well-suited for application to hydrocarbon fuels, and yields additional mass savings and efficiency increases when used in nonregenerative applications. A companion paper [23] details the technologies and trades associated with the hybrid SOFC power system for this proposed demonstrator program.

To gain a feel for power system scaling, Boeing conducted a scaling study to provide volume, mass, and efficiency metrics associated with different required power levels. The SOFC portion of the hybrid system could be sized to provide takeoff, climb, or cruise power, with the balance of power coming from an internal battery (hence the "hybrid" nomenclature). As many of the light aircraft considered for the demonstrator baseline use a limited set of approved gasoline-powered aviation engines, the basic requirements for the power system output were anchored to the performance of these engines. Arguably, there are three major power classes of normally-aspirated aviation engines at this scale, in terms of maximum brake horsepower produced: 100hp (e.g., Rotax 912S [24]), 180hp (e.g., Lycoming O-360-A4M [25]), and 310hp (e.g. Continental IO-550-N [26]). These power ratings represent maximum output on a sea level standard day, and do not consider drops in output to the propeller due to accessories (alternator, propeller governor, vacuum pump, etc.). These maximum power levels are typically only realized during takeoff or contingency conditions; instead, cruise flight for most of these aircraft takes place between $55-75 \%$ of rated power. The power levels for the hybrid system were therefore sized to these reduced power levels, which included a $10 \%$ reduction to account for the elimination of shaft-driven accessories and a "flat rating" of approximately 2,000 feet in density altitude. The resulting power requirements are given in Table 1.

Table 1: Power system sizing requirements for primary propulsion.

\begin{tabular}{|lccc|}
\hline Replacement Class & $\begin{array}{c}\text { Rotax 912S } \\
\text { (Nominally 73.5kW) }\end{array}$ & $\begin{array}{c}\text { Lycoming O-360-A4M } \\
\text { (Nominally 134.3kW) }\end{array}$ & $\begin{array}{c}\text { Continental IO-550N } \\
\text { (Nominally 231kW) }\end{array}$ \\
\hline Takeoff (2-5min), kW & 66 & 121 & 208 \\
\hline Cruise Climb (10+ min), kW & 56 & 103 & 176 \\
\hline Cruise (indefinite), kW & 40 & 79 & 135 \\
\hline
\end{tabular}

In addition to the amount of power needed for propulsion, each aircraft would need approximately $1.2-2.4 \mathrm{~kW}$ to drive electrical accessories, including avionics, electrical actuators, and propeller governors (if installed). These systems would likely be at a much lower voltage than the propulsion system, but would still be charged from the hybrid SOFC-electric powertrain.

\section{Electric Powertrain Development}

Electric powertrains are an area of ongoing research both in and outside of NASA, and have advanced to a reasonable level of maturity. To keep risk and cost reasonable, the demonstrator will use a suitable Commercial OffThe-Shelf (COTS) or near-COTS solution for the electric motors, drives, gearboxes, cooling system, and propeller. Aircraft propeller torque and speed requirements at takeoff and cruise are important for system sizing, as well as any volume and mass constraints. These requirements narrow the trade space and allow for the selection of a motor and corresponding power electronics topology, which will feed off the direct current bus from the power system.

For the initial search, the three engines referenced in Table 1 above were scrutinized to identify appropriate torque and power requirements. Initially, only direct-drive options were considered, as this enables the lowest-risk installation (although with increased weight and/or loss of efficiency). Additionally, the initial motors considered for the feasibility assessment were COTS options - which were generally not purpose-built for aviation (e.g. heavy).

Certainly, one of the major issues associated with direct drive motors is that the high torque required to drive the propeller results in a heavy motor that may not be operating at its most efficient point. For example, Figure 2 shows 
the power requirements for two motors (YASA 400 [27] and YASA 750 [28]) overlaid with the estimated power requirements of the Rotax $912 \mathrm{~S}$ gasoline engine vs. propeller speed. (For reference, the Rotax $912 \mathrm{~S}$ is unusual in light aviation engines, as it employs a 2.43:1 gearbox between the engine and the propeller. The O-360 and IO-550 motors referenced in this study are both direct drive.) Although this figure shows that the YASA 400 should meet the power requirements vs. propeller speed as a replacement for the Rotax $912 \mathrm{~S}$, the torque vs. propeller speed curves shown in Figure 3 tell a different story. Here, it becomes apparent that the heavier YASA 750 may be necessary unless a lower-torque, higher RPM propeller is used, or a gearbox is added to the motor.

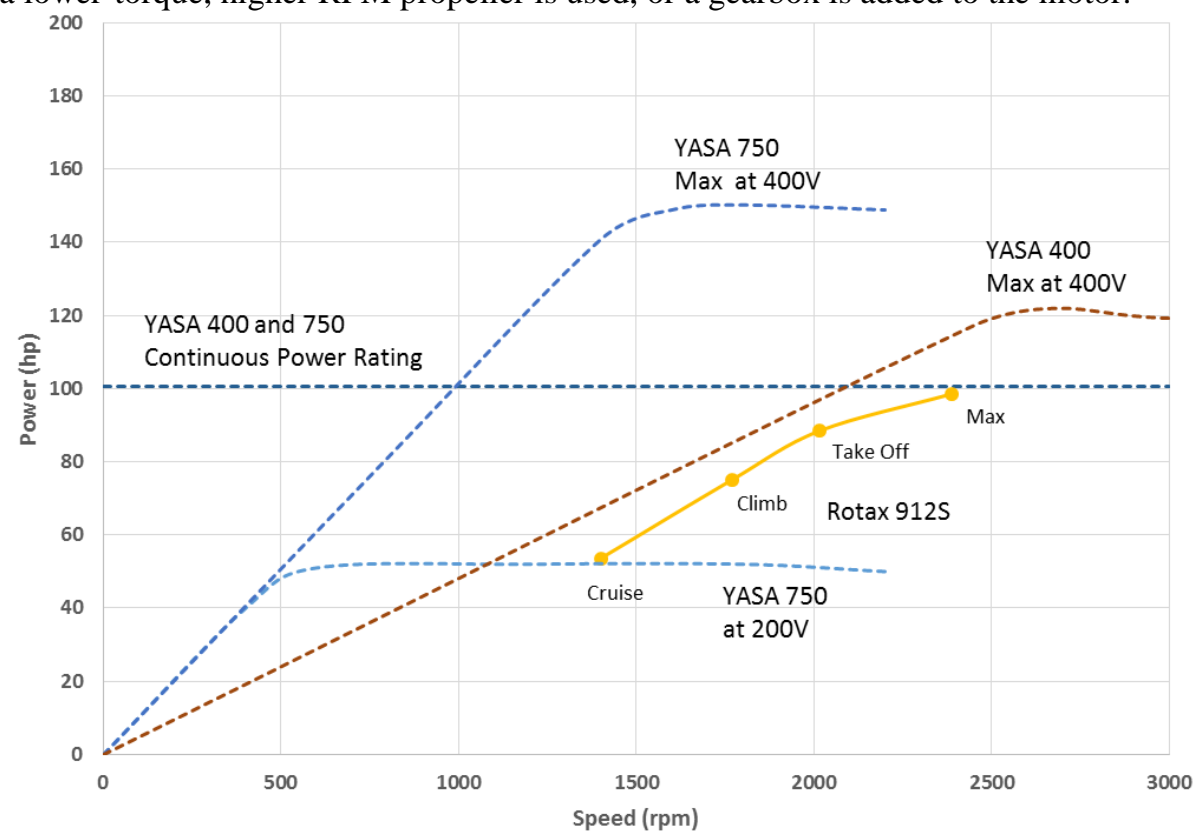

Figure 2: Shaft power vs. propeller speed for two candidate replacement electric motors as compared to Rotax 912S.

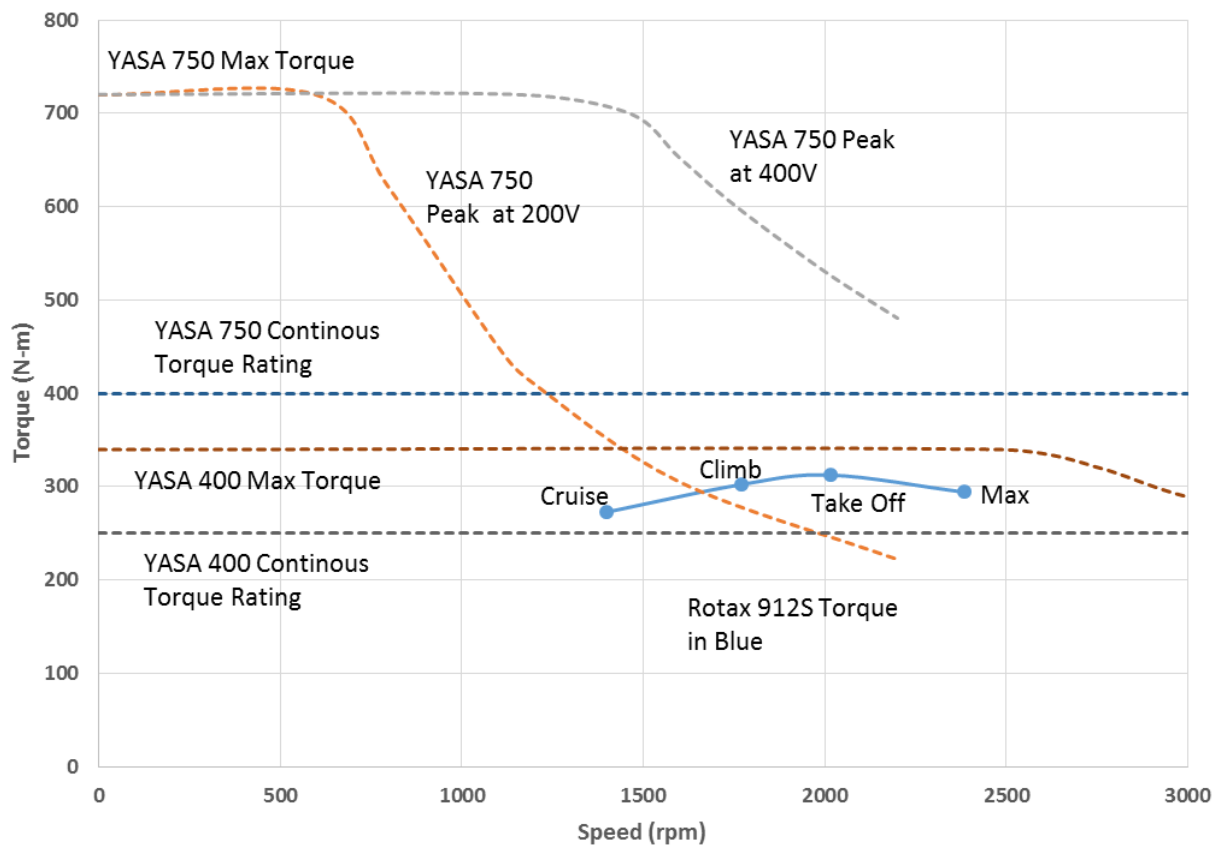

Figure 3: Shaft torque vs. propeller speed for two candidate replacement electric motors as compared to Rotax 912S.

Not surprisingly, the torque requirements imposed by a direct-drive propeller ended up driving the COTS motor selection. Thus, the power capabilities of many of the motors selected as part of the initial scaling studies were significantly higher than the power output necessary. A snapshot of the candidate motors and their associated

American Institute of Aeronautics and Astronautics 
parameters are given in Table 2. It should be noted that one major difference between ICEs and electric motors is that electric motors can have contingency power and torque ratings over $50 \%$ in excess of their maximum continuous values; it is usually the motor cooling in this case that limits maximum continuous power and torque. Hence, while some motors may seemingly have lower maximum continuous torque values, some consideration was made for the amount of time the motor would need to operate at higher torque (for example, takeoff).

Table 2: Initial electric motor parameters for three representative aviation engine replacements.

\begin{tabular}{llcccc} 
Replacement Class & Electric Motor & Mass & $\begin{array}{c}\text { Max. Cont. } \\
\text { Power }\end{array}$ & $\begin{array}{c}\text { Max. Cont. } \\
\text { Torque }\end{array}$ & $\begin{array}{c}\text { Efficiency } \\
\text { at Cruise }\end{array}$ \\
\hline Rotax 912S & YASA 750 [28] & $33 \mathrm{~kg}$ & $100 \mathrm{~kW}$ & $400 \mathrm{~N}-\mathrm{m}$ & $92 \%$ \\
Lycoming O-360-A4M & UQM PowerPhase HD 250 [29] & $83 \mathrm{~kg}$ & $150 \mathrm{~kW}$ & $360 \mathrm{~N}-\mathrm{m}$ & $92 \%$ \\
Continental IO-550N & Siemens 261kW [30,31] & $50 \mathrm{~kg}$ & $261 \mathrm{~kW}$ & $1000 \mathrm{~N}-\mathrm{m}$ & $95 \%$ \\
\hline
\end{tabular}

In all cases, the motors in Table 2 are liquid cooled, and the mass associated with the motors does not include the mass of the cooling system or the motor controller (inverter). Addition of this equipment will increase the total powertrain weight by $10 \mathrm{~kg}$ of more, depending on the architecture. Also of note, the motors selected here are quite heavy, with the exception of the Siemens $261 \mathrm{~kW}$ motor, which achieves a specific power output of over $5 \mathrm{~kW} / \mathrm{kg}$. However, this motor is not yet for sale on the open market, and has only been announced in press releases [30]. Unfortunately, other direct-drive motors in this power and torque class were so heavy that they were not included in the comparison table. The fact that a purpose-built aviation electric motor could achieve such high power-to-weight ratios is encouraging, however, and other concepts will certainly need to be considered once the conceptual design of the demonstrator to support a funded flight program begins in earnest. In the meantime, the heavier masses were used as a hedge to provide additional mass margin.

In addition to the motors listed in Table 2, Siemens has been developing a geared $65 \mathrm{~kW}$ motor [31] suitable for aviation applications that, until recently, was used in the Pipistrel Alpha Electro. This motor, at $13 \mathrm{~kg}$ (including gearbox and inverter), again achieved near $5 \mathrm{~kW} / \mathrm{kg}$, showing the possibilities associated with purpose-built aviation electric motors. Another potential low-cost concept, albeit at higher mass, would be to marry the gearbox from a Rotax 912S with a YASA 400 motor, which would yield acceptable torque at higher efficiency, though perhaps at a wash in mass vs. the YASA 750. These, and other options, will persist as the demonstrator program moves forward.

\section{Demonstrator Candidates}

More than a dozen candidate aircraft were considered as retrofit candidates, ranging from very light single engine aircraft to twin-engine designs. All used powerplants within the range of the replacement classes mentioned above, and were scrutinized considering the power architectures defined from the Boeing scaling study. Of these aircraft, six specific configurations were evaluated through more thorough analysis to identify any salient trends. To conduct this evaluation, the following ground rules were used:

- Revised gross weight (after retrofit) cannot exceed nominal gross weight - Though it is certainly possible to operate certified aircraft at higher gross weights than shown on the type certificate (particularly since NASA is its own airworthiness authority within its test ranges), the gross weight limits of the candidate aircraft were held fixed to the certified aircraft to level the playing field. If reasonable performance could not be possible at the posted gross weight, the aircraft would not be considered suitable.

- Revised maximum zero fuel weight cannot exceed nominal maximum fuel weight - Some aircraft have a maximum fuel weight that is less than the gross weight of the aircraft, and this was also respected to reduce/eliminate need for more extensive structural analyses.

- Crew and instrumentation mass held at 180kg - This enables a reasonable-sized test pilot and associated equipment along with an instrumentation mass budget of $70-80 \mathrm{~kg}$, which is reasonable when compared to previous flight experiments at this scale.

- Mass of gasoline engine and associated systems included in exchange mass - The mass associated with the (fairly heavy) gasoline engine, stock electrical system (starter, low-voltage battery, etc.), and other accessories such as oil coolers and engine instrumentation were all considered as part of the "exchange mass" available for the electric powertrain and hybrid-SOFC power system.

- Mass of hybrid power system estimated based on SOFC sized for cruise power levels - As discussed above, the hybrid SOFC-electric power system was evaluated based on different sizing conditions. The most effective system, detailed in the Boeing companion paper [23], sized the SOFC for cruise power 
output plus battery changing loads, and sized the battery to augment SOFC output for takeoff and climb. The scaling and size estimates from the Boeing study were used to estimate the total mass of the power system.

\section{Lancair Columbia 300 at Cessna TTx Gross Weight}

A promising candidate is NASA Langley's Lancair Columbia 300 [32] shown in Figure 4. This aircraft was purchased for the NASA Small Aircraft Transportation System Program and is currently in flyable storage, so making substantial changes to its airframe will not impact other test programs. It is powered by a $310 \mathrm{hp}(230 \mathrm{~kW})$ gasoline engine and has approximately 1,000 pounds of useful load (the total weight available for the pilot, passengers, payload, and fuel). Removing the motor, starter, and other associated equipment yields another 500+ pounds in exchange weight to consider for the electric power system. Unfortunately, the empty weight of the retrofitted system would exceed the maximum zero fuel weight of the Columbia 300. However, the current production version of the Columbia 300, branded the Cessna TTx [33], has a higher maximum allowable zero fuel weight and maximum gross weight. As such, it may be possible to modify NASA's existing asset and take advantage of the higher gross weight.

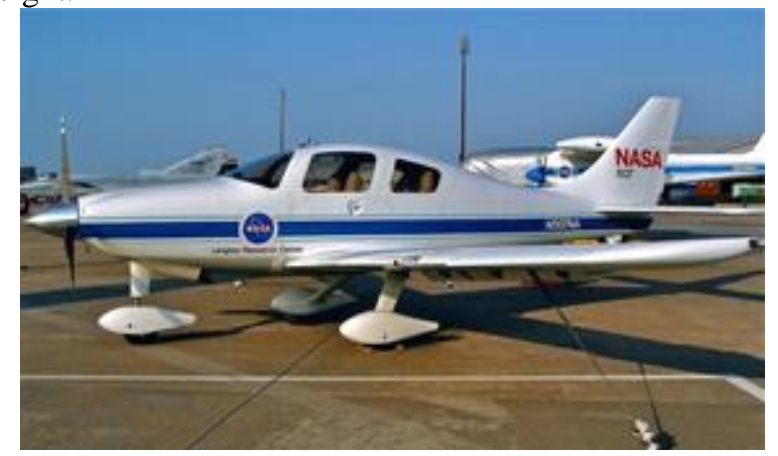

Figure 4: NASA Langley's Lancair Columbia 300.

\section{Cessna 172N/P with SuperHawk Supplemental Type Certificate}

The Cessna 172 is the most-produced aircraft in the world, with over 40,000 aircraft produced, and variants still in production today. It is used as an entry-level single-engine aircraft by many pilots, and is used for flight training as well as recreational and limited business transportation. Among its many variants, several Supplemental Type Certificates (STCs) are available, including those that boost the gross weight of the aircraft with limited modifications. One such STC offered by Penn Yann Aero boosts the gross weight of older Cessna 172s to 2,550 pounds by, among other things, increasing engine power from 160hp to 180hp [34]. This STC can result in over 1000 pounds of useful load. The estimated exchange weight is over 350 pounds, yielding an impressive amount of weight available at reduced power levels compared to the Columbia 300, enabling a smaller system.

\section{Tecnam P2006T}

The Tecnam P2006T is a modern, light twin engine aircraft powered by two Rotax 912S gasoline engines. Like the Cessna 172, it is used for flight training (largely for multiengine ratings), but is also used in recreational and limited business transportation roles. It has a useful load of nearly 1000 pounds and an exchange weight of over 400 pounds. A highly modified Tecnam P2006T is being considered for NASA's SCEPTOR Distributed Electric Propulsion Flight Demonstrator [7], so it may be possible to leverage the electric propulsion work for SCEPTOR for a future SOFC flight demonstrator. Two different configurations of the Tecnam P2006T were considered - one with a spilt hybrid SOFC-electric power system (one for each motor), and a configuration with a single, larger combined hybrid power system that provided power to both motors. The latter takes advantage of the "economy of scale," but would require the power system moved into the crew compartment behind the test pilot.

\section{Cessna 337}

The Cessna 337 is a unique twin-engine design that utilizes a tandem "push-pull" configuration; that is, both engines are along the centerline, with one forward of the crew compartment, and one aft. This eliminates thrust asymmetry due to engine failures, and could enable a replacement of a single engine with an electric motor powered by the hybrid SOFC-electric power system. The other engine would remain on the airframe, and provides a level of risk mitigation in the event of a power failure of the experimental electric powertrain or power system. As a larger 
aircraft, the Cessna 337 has a useful load of approximately 1600 pounds, with an additional exchange weight of around 350 pounds for the single engine (given that some of the other engine-driven electrical systems will remain).

\section{North American/Rockwell OV-10}

The final aircraft considered did not actually replace a primary propulsion system, but rather would leverage a podded installation of a completely independent electric propulsion system. The OV-10 is a large twin turboprop aircraft (Figure 5), and NASA does have two such assets in storage. By leaving the twin turboprop engines in place, the OV-10's large payload capacity enables freedom to select a range of options that could be sized to anything that could fit, given that the electric motor would not need to provide primary propulsion to the aircraft. The high tails and short fuselage of the OV-10 enable a podded test propulsor to be located above and aft of the crew compartment. Another interesting risk mitigation is the availability of ejection seats, given that these were previously surplus military aircraft.

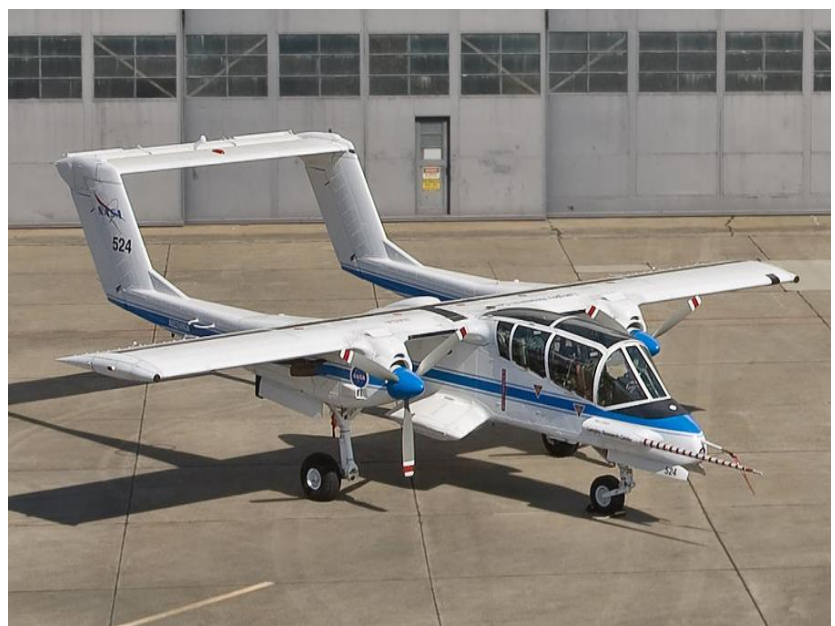

Figure 5: One of NASA's North American/Rockwell OV-10A Broncos.

\section{E. Initial Concept Selection}

Each of the concepts discussed above represents a feasible, albeit potentially challenging, platform for flight demonstration of a hybrid SOFC-electric power system. To further identify concepts, the team conducted a modified Pugh assessment of the six remaining alternatives (the Tecnam was really two alternatives, given the spilt vs. centralized power system options). This Pugh analyses considered the Columbia 300 as the baseline concept, and scored each concepts via the criteria from subsection A according to the following subjective criteria:

- 1 - Much worse than baseline,

- 2 - Somewhat worse than baseline,

- 3 - More or less equivalent to baseline,

- 4 - Somewhat better than baseline, and

- 5 - Much better than baseline.

Additionally, each metric was assigned an importance value - High, Medium, or Low. The scores for each concept were taken as a weighted sum of importance and Pugh criteria, where metrics labeled as High importance resulted in a 3x multiplier, Medium importance a $2 \mathrm{x}$ multiplier, and Low importance as a 1x multiplier. The resulting Pugh evaluation and weighted scores are given in Figure 6.

Overall, the results showed a few trends. First, no single concept was truly awful - all seemed to be a reasonable compromise for each of the demonstration criteria. Four of the concepts - the Cessna 172 with SuperHawk STC, Tecnam P2006T with single power system, Cessna 337, and OV-10, all gave similar results enough to stand out slightly from the others. Surprisingly, the Columbia 300, which served as the original point of departure for this exercise, came in lower. This is because potential issues with integration into the limited volume and balance envelope of the aircraft led to increased risk for integration of the propulsion and power system as compared to the other alternatives. Additionally, while it is encouraging that the Siemens motor exists at the appropriate power level at a very competitive weight, it is not yet available on the market, nor does it have a significant amount of test data 
that has been published. Given the lack of other suitable motors, this uncertainty is reflected in the Pugh evaluation. As more information on the motors becomes available, the Columbia 300 may become a more attractive option.

\begin{tabular}{|c|c|c|c|c|c|c|c|}
\hline Criteria & 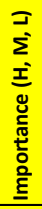 & 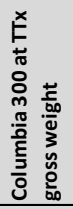 & 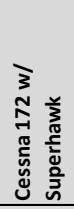 & 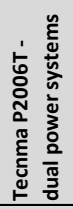 & 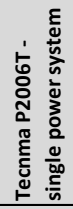 & 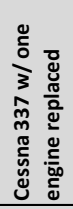 & 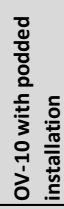 \\
\hline Airframe acquisition \& NASA processing: cost impact to program & $\mathrm{M}$ & 3 & 2 & 2 & 2 & 2 & 1 \\
\hline Airframe acquisition \& NASA processing: schedule impact to program & $\mathrm{H}$ & 3 & 2 & 3 & 3 & 2 & 1 \\
\hline Airframe acquisition \& NASA processing: uncertainty/risk impact to program & $\mathrm{H}$ & 3 & 3 & 2 & 2 & 3 & 1 \\
\hline Propulsion (motor, propeller, and accessories): cost impact to program & $\mathrm{M}$ & 3 & 5 & 2 & 2 & 3 & 4 \\
\hline Propulsion (motor, propeller, and accessories): schedule impact to program & $\mathrm{H}$ & 3 & 5 & 3 & 3 & 3 & 4 \\
\hline Propulsion (motor, propeller, and accessories): uncertainty/risk impact to program & $\mathrm{H}$ & 3 & 5 & 4 & 4 & 4 & 5 \\
\hline Power system (SOFC \& balance of plant): cost impact to program & $\mathrm{M}$ & 3 & 4 & 2 & 5 & 4 & 4 \\
\hline Power system (SOFC \& balance of plant): schedule impact to program & $\mathrm{H}$ & 3 & 3 & 2 & 4 & 3 & 4 \\
\hline Power system (SOFC \& balance of plant): uncertainty/risk impact to program & $\mathrm{H}$ & 3 & 3 & 3 & 4 & 3 & 4 \\
\hline Number of US vs. foreign manufacturers for demonstrator \& components & $\mathrm{M}$ & 3 & 4 & 3 & 3 & 4 & 4 \\
\hline Mass and volume margin with new motor \& power system & $\mathrm{H}$ & 3 & 4 & 4 & 5 & 5 & 5 \\
\hline Aircraft range with fuel at maximum gross weight & $\mathrm{L}$ & 3 & 2 & 3 & 3 & 3 & 3 \\
\hline Cruise speed & $\mathrm{L}$ & 3 & 1 & 2 & 2 & 3 & 3 \\
\hline Safety of flight impact & $\mathrm{H}$ & 3 & 3 & 4 & 2 & 5 & 4 \\
\hline Public perception ("wow" factor) & $\mathrm{M}$ & 3 & 2 & 3 & 3 & 1 & 1 \\
\hline TOTAL WEIGHTED SCORE (higher is better) & & 108 & 121 & 104 & 116 & 118 & 118 \\
\hline
\end{tabular}

Figure 6: Modified Pugh evaluation matrix for demonstrator selection.

One factor that significantly boosted the attractiveness of the Cessna 172 with the SuperHawk STC was the fact that the baseline aircraft has a fixed pitch propeller. All of the other aircraft (save the podded installation on the OV10) would replace a hydraulically-driven constant-speed propeller. Certainly, it is possible to use a fixed pitch propeller for those applications, but it comes at a significant loss in performance that may otherwise make the system-level benefit appear less attractive.

The OV-10 podded installation, while initially attractive, does come with a fair amount of its own uncertainty and costs. The cost to bring these aircraft back to flightworthy status, including arming of the ejection seats, may make cost and schedule a more important issue. Hence, it was eliminated from consideration after many discussions with NASA's flight test pilots and maintenance personnel that care for these aircraft.

To move forward with the initial design, the team wanted to push towards replacement of primary propulsion to identify the "pain points" associated with sizing the power system to fit within the mass and volume constraints on the retrofit aircraft. Therefore, the Cessna 337 was also dropped, though (like the OV-10), may be considered for future programs as programmatic and technical risk tolerance (or lack thereof) is clarified during demonstrator program maturation. Thus, the Cessna 172 with SuperHawk STC emerged as the preferred candidate, with the Tecnam P2006T as a backup, should the volume and mass constraints of the Cessna prove too cumbersome. Due to availability of the asset, the Columbia 300 was also carried through as well.

\section{F. Demonstrator Performance Estimates}

It is now possible to estimate the performance of the demonstrator aircraft through a fairly simple analysis of the masses and inspection of pilot operating handbook data. Table 3 lists the pertinent data and assumptions related to the candidate demonstrator performance. Note that the fuel mass to maximum gross weight metric was calculated assuming the crew and instrumentation mass of $180 \mathrm{~kg}$, as specified in the initial assumptions. The fuel flow was calculated based on the cruise efficiency of the motors, and the fuel-to-electric efficiency was calculated for the hybrid SOFC-electric power system. An additional multiplier was added to the cruise power level to account for the need to charge the buffer battery in the hybrid system during cruise.

All of these configurations, based on the current estimates for system sizes, are able to show over a $40 \%$ reduction in fuel flow by mass at cruise, and over a $50 \%$ reduction in fuel flow on a volumetric basis. This latter difference is due to the use of low-sulfur diesel fuel, rather than lower-density aviation gasoline, as the onboard reactant. As discussed in the companion Boeing paper [23], the low-sulfur fuel is necessary to preserve highefficiency operation of the SOFC in the power system. This is a formulation that is similar to jet fuel but without the high allowable sulfur content, and is available as diesel fuel at virtually every filling station in the United States. The difference between the volumetric fuel flow is important to note, as fuel is often priced by volume, not by weight. As such, if fuel costs were to be identical per gallon, the concepts described in Table 3 would all meet or exceed the program goals of a demonstrator with a reduction of $50 \%$ in fuel costs. In fact, it is likely that diesel sold at the 
airport would in fact be cheaper per unit volume than aviation gasoline, much as jet fuel is typically cheaper at most airports due to its greater supply. With these differences, even greater operational cost savings could be realized.

Table 3: Performance estimates for promising demonstrator configurations.

\begin{tabular}{|lccc|} 
& $\begin{array}{c}\text { Cessna 172P w/ } \\
\text { SuperHawk STC }\end{array}$ & $\begin{array}{c}\text { Tecnam P2006T w/ } \\
\text { single power system }\end{array}$ & $\begin{array}{c}\text { Columbia 300 at } \\
\text { Cessna TTx weight }\end{array}$ \\
\hline Takeoff gross mass, kg & 1159 & 1230 & 1636 \\
\hline Typical unmodified empty mass, $\mathbf{~ k g}$ & 695 & 780 & 1079 \\
\hline Unmodified fuel flow at cruise, $\mathbf{k g} / \mathbf{h r}$ & 25 & 26 & 39 \\
\hline Exchange mass, kg & -161 & -185 & -240 \\
\hline Hybrid power system mass, kg & 269 & 294 & 439 \\
\hline Electric powertrain mass, $\mathbf{~ k g}$ & 100 & 100 & 60 \\
\hline Fuel mass remaining to gross weight, kg & 76 & 61 & 22.1 \\
\hline Estimated cruise fuel flow, kg/hr & 13.4 & 13.6 & $-43 \%$ \\
\hline Change in cruise fuel flow, \% mass & $-46 \%$ & $-48 \%$ & $-50 \%$ \\
\hline Change in cruise fuel flow, \% volume & $-54 \%$ & $-55 \%$ & \\
\hline
\end{tabular}

In all of these cases, the higher weight of the hybrid power system results in an inability to utilize the full fuel volume available on each aircraft. However, the reduction in fuel flow is significant enough that each of these aircraft could fly for several hours at the cruise power settings prior to fuel exhaustion.

\section{G. Future Work}

Work is continuing on the conceptual design of a flight demonstrator retrofitted from an existing light aircraft design. The team is in the process of modeling the power system and powertrain to ensure that the appropriate spatial and mass/balance constraints are met. Additionally, one of the goals of taking this to a flight demonstration vs. ground power demonstration is to identify possible systemic issues with this new technology that could jeopardize the safety of flight. By considering a flight demonstrator, the team is required to think through and defend a system hazard analysis and safety case development for the entire system. This process is ongoing, as it is best to identify hazards early, when the design of the demonstrator is more flexible.

\section{Conclusions}

Electric motors may offer compelling advantages when used for primary propulsion, but the increased weight of the onboard energy storage system, lack of supporting infrastructure at airports, and lack of operational data all act to stymie adoption of electric propulsion. A better battery will not resolve infrastructure or certification issues, and with slow adoption rates, either concern will not be rectified in short order. Traditional approaches that convert infrastructure-friendly fuels to electricity (such as large gasoline-powered generators) do so at an efficiency that is not much better than the simple combustion-to-shaft power efficiency seen with today's aircraft. To overcome the multiple barriers to adoption of electric aircraft, a novel concept is needed that can dramatically increase the efficiency of conversion of traditional fuels to electricity.

This paper proposes a hybrid power system approach that leverages ongoing research into Solid Oxide Fuel Cells as a high-efficiency means to convert hydrogen derived from reformation of traditional hydrocarbon fuels to electricity onboard the aircraft. The use of these traditional fuels at a greatly increased efficiency allows for much longer range and endurance amongst aircraft with electric primary propulsion, and has the potential to offer utility to a much broader sector of the aviation market much sooner. This could lead to an increase in adoption rate of aircraft with electric primary propulsion, which would be an important certification pathway for larger, more complex aircraft that wish to use electric propulsion.

This investigation considers a balanced demonstration program that could be conducted for maximum impact, with controlled risk and cost. By targeting the performance and utility demanded of an early adopter market, this demonstrator program will kick off adoption of electric primary propulsion for aircraft and establish a much-needed operational basis for certification of larger, commercial aircraft. The demonstrator choices and technology concepts were selected from a blend of largely COTS motors and airframes to minimize development, and focus risk on the development of the hybrid SOFC-electric power system and integration into the airframe. This reduces the benefit that could be realized by electric propulsion, but showcases the impact of this approach on an "apples-to-apples" basis between the performance of capabilities of the unmodified aircraft and the selected demonstrator platform. 
The performance of the selected demonstrator concepts shows that it is quite possible to achieve a $50 \%$ or greater reduction in fuel costs for light aircraft. As fuel tends to be the largest direct operating cost associated with light aircraft (it can be half, and perhaps even more, depending on fuel price fluctuation), this can significantly reduce the operational cost for aircraft equipped with this new technology. Given the potential higher reliability of electric motors, other direct and indirect operating costs (e.g. maintenance cost) may be reduced as well. These substantial reductions in operating cost will appeal to early adopters in the light aircraft market, particularly if the payback period of the difference in up-front cost between the gasoline engine and the electric powertrain and power system is well within the aircraft's operational lifetime. Such early adopters will enable more rapid accumulation of certification data to enable application of these technologies to larger, commercial aircraft, either as a means of primary propulsion or for onboard electrical power generation for other electronic systems.

An added benefit of the hybrid SOFC-electric power system is the potential for a major reduction in emissions. The SOFC operates at $600-800^{\circ} \mathrm{C}$, which is certainly a high temperature, but is much lower than the temperatures seen in internal combustion engines. Typical combustion temperatures result in the formation of oxides of nitrogen $\left(\mathrm{NO}_{\mathrm{x}}\right)$ due to dissociation of nitrogen molecules in ambient air, whereas the much-lower SOFC operating temperature will not foment such dissociation and $\mathrm{NO}_{\mathrm{x}}$ formation. As such, the hybrid SOFC-electric power generation scheme will result in effectively zero $\mathrm{NO}_{\mathrm{x}}$ emissions. This can be especially important as the hybrid SOFC-electric later moves into larger commercial aircraft as Auxiliary Power Units (APUs), since a substantial portion of surface $\mathrm{NO}_{x}$ emissions at major airports are due to APU use on the ground. Furthermore, while this hybrid power system concept still utilizes hydrocarbon fuels, a savings of 50\% in fuel by mass will effectively result in a $50 \%$ reduction in carbon emissions. As the number of equipped aircraft grows, the environmental impact of the light aircraft fleet will drop precipitously. Larger aircraft equipped with hybrid SOFC APUs could enable a substantial drop in airport surface carbon emissions due to APU use.

\section{Acknowledgments}

This work is funded under the NASA Aeronautics Research Mission Directorate Seedling Fund, administered by the NASA Aeronautics Research Institute (NARI). The authors would like to thank NARI, including Michael Dudley, Koushik Datta, and Deborah Bazar, for their assistance and support throughout this effort.

\section{References}

1. M. Moore, K. Goodrich, J. Viken, J. Smith, B. Fredericks, T. Trani, J. Barraclough, B. German, M. Patterson, "High-Speed Mobility through On-Demand Aviation," AIAA 2013-4373, Aviation Technology, Integration, and Operations Conference, Los Angeles, CA, August 2013.

2. N. K. Borer, M. D. Moore, A. R. Turnbull, "Tradespace Exploration of Distributed Propulsors for Advanced On-Demand Mobility Concepts," AIAA-2014-2850, AIAA Aviation, Atlanta, GA, June 2014.

3. N. K. Borer, M. D. Moore, "Integrated Propeller-Wing Design Exploration for Distributed Propulsion Concepts," AIAA 2015-1672, AIAA SciTech, Kissimmee, FL, 5-9 January 2015.

4. M. Moore and B. Fredericks, "Misconceptions of Electric Propulsion Aircraft and their Emergent Aviation Markets," AIAA 2014-0535, 52 ${ }^{\text {nd }}$ Aerospace Sciences Meeting, National Harbor, MD, January 2014.

5. Airbus Group, “Airbus E-Fan: the future of electric aircraft," http://www.airbusgroup.com/int/en/innovation-environment/efan-the-electric-plane.html, accessed 13 May 2015.

6. M. Grady, "Pipistrel Introduces Alpha Electro," http://www.avweb.com/avwebflash/news/Pipistrel-Introduces-AlphaElectro-223852-1.html, accessed 13 May 2015.

7. G. Warwick, "NASA's Electric-Propulsion Wing Test Helps Shape Next X-Plane,” Aviation Week \& Space Technology, 24 August 2015.

8. J. Hemmerdinger, "Three 'miracles' required for mainstream electric-powered aircraft, says P\&W," http://www.flightglobal.com/news/articles/three-39miracles39-required-for-mainstream-electric-powered-aircraft-says399640/, accessed 13 May 2015.

9. ASTM International, Standard Specification for Leaded Aviation Gasolines, ASTM D910, 2015.

10. ASTM International, Standard Specification for Aviation Turbine Fuels, ASTM D1655, 2015.

11. AA Portable Power Corporation, "Hi-Power Li-Po Packs," http://www.batteryspace.com/hi-powerli-popacks.aspx, accessed 13 May 2015.

12. Tesla, "Battery: Increasing Energy Density Means Increasing Range," http://my.teslamotors.com/roadster/technology/battery, accessed 13 May 2015.

13. Pipistrel Aircraft, “Taurus Electro," http://www.pipistrel.si/plane/taurus-electro/faq, accessed 15 May 2015.

14. R. A. McDonald, "Establishing Mission Requirements Based on Consideration of Aircraft Operations," Journal of Aircraft, 50(3) 741:751, 2013.

15. Federal Aviation Administration, "National Plan of Integrated Airport Systems (NPIAS), (2011-2015)," Report of the Secretary of Transportation to the United States Congress, 27 September 2010.

13

American Institute of Aeronautics and Astronautics 
16. M. Chambers, "Transportation Safety by the Numbers," Bureau of Transportation Statistics, http://www.rita.dot.gov/bts/sites/rita.dot.gov.bts/files/publications/by_the_numbers/transportation_safety/index.html, accessed 14 May 2015.

17. Federal Aviation Administration, "System Safety Analysis and Assessment for Part 23 Airplanes," Advisory Circular 23.1309-1E, 17 November 2011.

18. Federal Aviation Administration, "System Design and Analysis," Advisory Circular 25.1309-1A, 21 June 1988.

19. ASTM International, "Committee F39 on Aircraft Systems," http://www.astm.org/COMMITTEE/F39.htm, accessed 15 May 2015.

20. H. D. Kim, G. V. Brown, J. L. Felder, "Distributed Turboelectric Propulsion for Hybrid Wing Body Aircraft," 2008 International Powered Lift Conference, London, England, July 2008.

21. National Aeronautics and Space Administration, "SBIR/STTR: Low Emissions Propulsion and Power," http://sbir.gsfc.nasa.gov/content/low-emissions-propulsion-and-power, accessed 15 May 2015.

22. N. Borer, "A Heavy Fuel Solid Oxide Fuel Cell-Enabled Power System for Electric Flight," AHS/AIAA/NASA Transformative Vertical Flight Workshop, Moffett Federal Airfield, California, 3-4 August 2015. Electronic presentation available at http://nari.arc.nasa.gov/sites/default/files/attachments/Borer-TVFW.pdf, accessed 9 November 2015.

23. T. Stoia, "A Highly Efficient Solid Oxide Fuel Cell Power System for an All-Electric Commuter Airplane Flight Demonstrator," AIAA SciTech, San Diego, California, June 2016.

24. BRP-Powertrain GmbH\&Co., "Operators Manual for ROTAX ${ }^{\circledR}$ Engine Type 912 Series,” OM-912, 2013.

25. AVCO Lycoming Division, “Operator's Manual: AVCO Lycoming O-360 and Associated Models,” third edition, 1976.

26. Continental Motors, Inc., "Continental ${ }^{\circledR}$ Aircraft Engine Permold Series Engine Installation and Operation Manual," Publication OI-16, 2011.

27. YASA Motors, "YASA 400 Advanced Axial Flux Motor," http://www.yasamotors.com/products/yasa-400/, accessed 9 November 2015.

28. YASA Motors, "YASA 750 Advanced Axial Flux Motor," http://www.yasamotors.com/products/yasa-750/, accessed 9 November 2015.

29. UQM Technologies, "UQM PowerPhase ${ }^{\circledR}$ HD," https://uqm.com/products/full-electric/production/commercial-vehicles/, accessed 9 November 2015.

30. Siemens, "Powerful Ultralight Motor for Electrically Powered Flight," http://www.siemens.com/innovation/en/home/pictures-of-the-future/mobility-and-motors/electromobility-electricallypowered-flight.html, accessed 9 November 2015.

31. K. Petermaier, "Electric Propulsion Components with High Power Densities for Aviation," AHS/AIAA/NASA Transformative Vertical Flight Workshop, Moffett Federal Airfield, California, 3-4 August 2015. Electronic presentation available at http://nari.arc.nasa.gov/sites/default/files/attachments/Korbinian-TVFW-Aug2015.pdf, accessed 9 November 2015.

32. C. T. Howell III et al., "The NASA Langley Research Center's General Aviation Baseline Research System," Digital Avionics Systems Conference, 2003.

33. Textron Aviation, "Cessna TTx - The Fastest Fixed Gear Single Engine Plane in the World,” http://cessna.txtav.com/singleengine/cessna-ttx, accessed 10 November 2015.

34. Penn Yann Aero, "STCs and Horsepower Upgrades," https://www.pennyanaero.com/stcs-hp-upgrades.php, accessed 10 November 2015. 